\title{
Corrosion Behavior of Heat Treated Nickel-Aluminum Bronze Alloy in Artificial Seawater
}

\author{
Ashkan Vakilipour Takaloo ${ }^{1}$, Mohammad Reza Daroonparvar ${ }^{2}$, Mehdi Mazar Atabaki ${ }^{1,3}$, \\ Kamran Mokhtar ${ }^{1}$
} ${ }^{1}$ Department of Materials Engineering, Faculty of Mechanical Engineering, Universiti Teknologi Malaysia, Johor, Malaysia; ${ }^{2}$ De-
partment of Materials Engineering, Faculty of Mechanical Engineering, Roudehen Branch, Islamic Azad University, Roudehen, Te-
hran, Iran; ${ }^{3}$ Institute for Materials Research, School of Process, Environmental and Materials Engineering, Faculty of Engineering,
University of Leeds, Leeds, UK.

Email:pmmmaa@leeds.ac.uk,m.mazaratabaki@yahoo.co.uk

Received June 28 $8^{\text {th }}, 2011$; revised August 11 $1^{\text {th }}$, 2011; accepted September $14^{\text {th }}, 2011$.

\begin{abstract}
The effect of microstructure of nickel-aluminum bronze alloy $(N A B)$ on the corrosion behavior in artificial seawater is studied using linear polarization, impedance and electrochemical noise tests. The alloy was heat treated in different heating cycles including quenching, normalizing and annealing. Microstructure of the specimens was characterized before and after heat treatment by optical microscopy and scanning electron microscopy. Results showed that the value of pearlite phase in the normalized alloy is much more than other specimens, leading to higher corrosion resistance. Polarization test showed that starting point of passivation in the polarization of the normalized alloy is lower than other specimens. The dissolution of Mn and Fe rich phases increased the Mn and Fe contents in solid solution, and this enhanced the passivation power of the surface of the alloy. The effect of the alloying elements was seen by a lower corrosion potential and an inflexion at around $280 \mathrm{mV}(S C E)$ in the polarization curve, indicating the preferential dissolution of some elements beyond that potential. The polarization curve showed that the anodic polarization behavior of the alloy in the solution was essentially controlled by the intermetallic phases, mainly containing $\mathrm{Cu}$. Two types of corrosion, pitting and selective corrosion, were observed in the specimens after being exposed to artificial seawater.
\end{abstract}

Keywords: Nickel-Aluminum Bronze Alloy, Heat Treatment, Corrosion, Microstructure

\section{Introduction}

Nickel-aluminum bronze known as NAB is a series of copper-based alloy with additions of $9 \%-12 \% \mathrm{Al}$ and $6 \% \mathrm{Ni}$ and $\mathrm{Fe}$. High corrosion resistance of this alloy has made it one of the most practical alloys in marine applications e.g. ship propellers $[1,2]$. The microstructure of the alloy consists of a $\mathrm{Cu}$-rich solid solution known as $\alpha$-phase and $\beta^{\prime}$-phase or martensitic $\beta$-phase, surrounded by lamellar eutectoid phase and a series of intermatallic $k$ phases [3 and 4]. Among the inermetallic compounds, $K_{I}$ phase is rosette shape which is rich in Fe, $K_{I I}$ phase is smaller than $k_{I}$ phase and form a dendritic rosette shape which distributed at the $\alpha / \beta$ boundaries, $K_{I I I}$ phase is lamellar shape and it forms at the boundary of $K_{I}$ phase and is rich in Ni and $K_{I V}$ phase is a fine Fe rich precipitations that forms in $\alpha$ phase [5]. Recently, a vast range of inves- tigation have been carried out to study the corrosion behavior of the cast nickel-aluminum alloy [6,7] and it has been found that optimum corrosion resistant of the alloy in seawater can be obtained by controlling the mictrostructure [8]. Corrosion of the bronze alloy in seawater have been investigated and the tendency of the cast alloy to corrode was attributed to the formation of $\beta^{\prime}$ phase which plays an anodic role compare to $\alpha$ matrix [9]. The complexity of the alloy with several intermetallic phases lead to a significant change in the development of the microstructures, which can result in extensive corrosion resistance in seawater. Results of salt spray test on corrosion behavior of the alloy indicated that corrosion resistance has been improved in the heat treatment sequences like aging, quenching, normalizing and annealing. Characterizing the microstructure showed that quenching transforms all $\beta$ phase into $\beta^{\prime}$ phase and aging results in 
precipitation of fine $k$ phases. On the other hand, annealing has lead to the transformation of $\beta^{\prime}$ martensite into $\alpha$ and $k$ phases [10]. Microstructure of the bronze alloy suffered from cavitation corrosion in seawater showed that the alloy was corroded by selective corrosion at the interface between $\alpha$ phase and intermetallic $K$ precipitates, however, $K$ precipitate-free zones were not considerably corroded. Crevice corrosion of the copper-based alloy was often associated with the formation of a $\mathrm{Cu}$-ion concentration cell and an accelerated attack at the exposed area adjacent to the crevice [11]. Meigh et al. [12] declared crevice corrosion occurs in the nickel-aluminum bronze when it is not cathodically protected. It has been reported that the rate of crevice corrosion of the alloy in seawater is about $0.7-1.0 \mathrm{~mm} \mathrm{y}-1[13,14]$. The corrosion resistance of the alloy is owned to a protective layer containing both $\mathrm{Al}$ and $\mathrm{Cu}$ oxides, with 900 to $1000 \mathrm{~nm}$ thickness $[15,16]$. The Al-rich oxide layer usually forms in the vicinity of the alloy and the $\mathrm{Cu}$-rich forms in the external regions. Oxides of $\mathrm{Ni}$ and $\mathrm{Fe}$, and a little $\mathrm{Cu}$ salts and $\mathrm{Cu}$ hydroxychlorides $\left(\mathrm{Cu}_{2}(\mathrm{OH})_{3} \mathrm{Cl}\right.$ and $\mathrm{Cu}$ $(\mathrm{OH}) \mathrm{Cl})$ exist on the surface of the alloy after exposing for long time to seawater. These oxide layers provide corrosion protection by mutually lessening the anodic dissolution reaction, stopping the ionic transport across the oxide layers, and a decrease in the rate of the cathodic reaction on the oxide layers. On the contrary to the many studies of the corrosion in seawater for the alloy, there has been small number of investigations to study the effect of heat treatment processes on the electrochemical kinetics at the surface of the alloy when it is exposed to seawater environment [17]. For example, Schüssler and Exner [11] conducted a research on the dissolution of a cast nickel-aluminum bronze alloy in seawater with considering a fixed velocity of electrolyte without a considerable contribution on the effect of microstructure on the corrosion. Kear et al. showed that both cathodic [16] and anodic [17] polarization can occur during the corrosion of the alloy in an aqueous solution. The anodic dissolution of the alloy showed significant dissolution of $\mathrm{Cu}$ with forming dichlorocuprous anion and the cathodic reaction showed four electron reduction of dissolved oxygen on the surface. However, at a mixed potential, the anodic kinetics are controlled by mass transfer and charge transport. As a result, the rate and mechanism of the corrosion are very susceptible to prior heat treatment processes. The protective nature of the alloy was attributed to the formation of $\mathrm{C}_{2} \mathrm{O}$ layer due to the history of its heat treatment. The reduction of the corrosion rate during the layer formation process was explained by means of the concurrent decrease both of the anodic reaction inside the growing $\mathrm{Cu}_{2} \mathrm{O}$ layer, and the cathodic reaction on its surface. Aluminum in pas- sivation was incorporated in the $\mathrm{Cu}_{2} \mathrm{O}$ lattice, reducing the rate of oxygen reduction on the $\mathrm{Cu}_{2} \mathrm{O}$ surface when the alloy exposed to a corrosive environment [17].

From another stand point, electronic tools like linear polarization have some drawbacks for the measurement of electrochemical properties. One of the main problems is the invasive character of the devices to the electrochemical systems of the metallic electrodes in aqueous solutions [18]. In this regard, the corrosion current density of metallic electrodes, corresponding to the opencircuit potential of the electrodes in the aqueous solution can be measured with zero resistance ammeter and linear polarization methods [19]. In zero resistance ammeter the corrosion current can be estimated with measuring current density of two similar metallic electrodes at the open-circuit potential of the electrodes in seawater without any external voltage on the electrodes. This process owned to the existence of electronic noise and loss of the electrical resistance across the interface between two electrodes and seawater. However, in the linear polarization method, the corrosion current density of electrode at the open-circuit potential of the electrode in artificial seawater can be measured with an external voltage. In this process, polarization resistance expands across the interface between the solid electrode and seawater. As one part of the present study concentrates on the results of electrochemical noise technique, the fluctuations of the current and potential were generated at the same time during the corrosion process. The most effective part of this test was the elimination of disturbing signals and the ability to avoid the artificial disturbances during the measurement. It was shown that the sensitivity of electrochemical noise measurement is considerably higher than other conventional methods in the case of localized corrosion process [20]. In this method, at different times the intensity of corrosion can be monitored and the noise resistance, the ratio of the standard deviations of the potential and current noise can be easily measured. The mechanism of the process is a competition course between breakdown and repassivation of the passive film with developing a pitting and an active corrosion process. In this state, forming unstable pits depends on the time and repassivation is the consequence of the shape and life of the unstable pits. For estimating power spectral density by the maximum entropy method, it is essential to choose the maximum order of the autoregressive accidental variable. If the order is small, the spectrum can be approximately flat and if the spectrum emerges noisier it shows the order is large [21]. In the statistical calculation of the noises, the highest noises called shot-noise were analyzed and the individual occurrences in the corrosion process were considered.

In the present study, the influence of different pre-heat 
treatments on the passivation behavior of nickel-aluminum bronze alloy is studied using linear polarization, impedance and electrochemical noise tests. The effect of heat treatment processes during corrosion of the alloy was evaluated by optical microscopic, scanning electron microscopy and X-ray diffraction analysis. It was found that normalizing of the alloy has a considerable effect in preventing the corrosion in artificial seawater.

\section{Experimental Details}

The nickel-aluminum bronze alloy (C95520) was cast according to ASTM B 148 standard and then cut into small pieces of dimensions $6 \mathrm{~mm} \times 6 \mathrm{~mm} \times 3.5 \mathrm{~mm}$. The composition of the alloy was determined by X-ray fluorescence spectrometry (XRF) and it is shown in Table 1.

Tensile strength and hardness of the substrate estimated experimentally shown the alloy has tensile strength of about $630 \mathrm{MPa}$ and hardness of $162 \mathrm{HV}$. The phase composition has been checked at high exposure times by X-ray diffractometry (XRD) in the BraggBrentano geometry, using $\mathrm{Cu}=\mathrm{K} \alpha$ radiation $(\mathrm{k}=$ $0.15404 \mathrm{~nm}$ ). The specimens were mechanically cleaned, degreased, immersed in an aqueous solution of $20 \%$ $\mathrm{HNO}_{3}$ and then dried and maintained for $24 \mathrm{~h}$ in a desiccator in excess of silica gel and in the last part of the cleaning process the alloy weighed. For preparing the aqueous solution, artificial seawater was made according to ASTM D 1141-98 standard. The combination of the compounds in the artificial seawater is given in Table 2.

The artificial seawater with $\mathrm{pH}$ of 8.26 , dissolved oxygen concentration of around $7.0 \mathrm{ppm}$ and conductivity of $59.8 \mathrm{mS} \mathrm{m}^{-1}$ was held at ambient temperature of $27^{\circ} \mathrm{C}$ during the test. Before accomplishing any corrosion test, the specimens were heat treated in different cycles. The applied heat treatment procedures for altering the microstructure of the alloy are given in Table 3 .

The specimens were mechanically polished with 0.2 $\mu \mathrm{m} \alpha$-alumina slurry and etched with the solution of $5 \mathrm{~g}$ $\mathrm{FeCl}_{3}+25 \mathrm{~mL} \mathrm{HC1}+50 \mathrm{~mL} \mathrm{H}_{2} 0$. X-ray diffraction test was performed to realize the intermetallic compounds in the heat treated specimens before and after corrosion tests. To perform the polarization test, the specimens were grounded, polished and degreased with acetone. To prevent other areas from exposing to seawater an area with a dimension of $1 \mathrm{~mm} \times 1 \mathrm{~mm}$ was chosen and other areas were protected with a polymeric adhesive. The ad- hesive prepared by combining cure polyamide and reinforcement shielded with BissWax in order to minimize the localized corrosion. General corrosion behavior e.g. oscillation in corrosion potential of the alloy was estimated using linear polarization with EG \& $\mathrm{G}$, model 237A corrosion system. The data recorded from this test was analyzed by MATLAB V7.0.0 software. The potential scanning rate was $0.5 \mathrm{mVs}^{-1}$ and when the potential reached to $800 \mathrm{mV}$, the scan was discontinued. In this test, $\mathrm{Ag} / \mathrm{AgCl}$ and $\mathrm{Pt}$ reference electrodes were used in a potential between -700 and $800 \mathrm{mV}$ setting in maximum value for 0.6 second. The platinum counter electrode enabled controlling the potentiostatic during the test. The recorded values of corrosion rate correspond to the average value from the specimens per exposure time. The passivation resistance layer was estimated with impedance test according to ASTM G 106-89 standard. In the test, potansiostat EG \& G, model 273A device was employed and M398 V.1.30 software was used for recording impedance data and drawing Bode curve during the test. To record the data from Nyquist test, $Z$ view-V3.0c software was employed. After linear polarization and impedance test, scanning electron microscope (SEM) was used for characterizing the microstructural changes. In electrochemical noise measurements, 22 small containers with a capacity of $400 \mathrm{cc}$ were prepared. The specimens were kept in $1 \mathrm{~cm}$ distance from each other in the container with protecting the environment from any vibration or pulsation. The anode to cathode area ratio was $1: 1$. The specimens were connected via electrical leads, with a gap of $1 \mathrm{~cm}$ and were mounted in a planar orientation on two non-metallic boards. The boards were immersed in artificial seawater. The current and potential were measured using a zero resistance ammeter, model SNAWA. Formation and destruction of passive film on the surface of specimens, initiated by pitting corrosion, was recorded by InstLinkPC software. The reference electrode was located in a free space between two of the specimens with the same applied pre-heat treatment process. Specimens held in artificial seawater for periods of $11,20,40,50$ and 75 days were tested in electrochemical noise examination (ZRA) for 1400, 2500, 4000, 4500 and 6000 second. Figure 1 shows how specimens were located in the container for corrosion tests.

Table 1. Chemical composition of nickel-aluminum bronze alloy (wt\%) after casting.

\begin{tabular}{|c|c|c|c|c|c|c|c|c|c|}
\hline \multirow{2}{*}{ Material } & \multicolumn{9}{|c|}{ Element Composition (wt\%) } \\
\hline & $\mathrm{Cu}$ & $\mathrm{Al}$ & $\mathrm{Fe}$ & $\mathrm{Ni}$ & $\mathrm{Si}$ & $\mathrm{Pb}$ & $\mathrm{Zn}$ & $\mathrm{Sn}$ & $\mathrm{Mn}$ \\
\hline Nickel-aluminum bronze alloy (NAB) & Bal. & 11.54 & 4.47 & 4.60 & 0.030 & 0.017 & 0.002 & 0.005 & 0.001 \\
\hline
\end{tabular}


Table 2. Chemical composition of artificial seawater based on ASTM D 1141-98 standard.

\begin{tabular}{ccc}
\hline Component & Quality & Unit \\
\hline $\mathrm{NaHCO}_{3}$ & 0.201 & $\mathrm{~g} / \mathrm{L}$ \\
$\mathrm{CaCl}_{2}$ & 1.158 & $\mathrm{~g} / \mathrm{L}$ \\
$\mathrm{MgCl}_{2} \cdot 6 \mathrm{H}_{2} \mathrm{O}$ & 11.112 & $\mathrm{~g} / \mathrm{L}$ \\
$\mathrm{SrCl}_{2} \cdot 6\left(\mathrm{H}_{2} \mathrm{O}\right)$ & 0.042 & $\mathrm{~g} / \mathrm{L}$ \\
$\mathrm{NaCl}$ & 25.534 & $\mathrm{~g} / \mathrm{L}$ \\
$\mathrm{Na}_{2} \mathrm{SO}_{4}$ & 4.094 & $\mathrm{~g} / \mathrm{L}$ \\
$\mathrm{KCl}$ & 0.695 & $\mathrm{~g} / \mathrm{L}$ \\
$\mathrm{KBr}$ & 0.201 & $\mathrm{~g} / \mathrm{L}$ \\
$\mathrm{H}_{3} \mathrm{BO}$ & 0.201 & $\mathrm{~g} / \mathrm{L}$ \\
$\mathrm{NaF}$ & 0.201 & $\mathrm{~g} / \mathrm{L}$ \\
\hline
\end{tabular}

Table 3. Applied heat treatment cycles to nickel-aluminum bronze alloy.

\begin{tabular}{|c|c|c|c|c|}
\hline Hear treatment & $\begin{array}{l}\text { Group } \\
\text { name }\end{array}$ & $\begin{array}{l}\text { Time } \\
(\mathrm{min})\end{array}$ & $\begin{array}{l}\text { Specimen } \\
\text { code }\end{array}$ & $\begin{array}{c}\text { Temperature } \\
\left({ }^{\circ} \mathrm{C}\right)\end{array}$ \\
\hline \multirow{3}{*}{$\begin{array}{l}\text { Quenching in } \\
\text { water, } 27^{\circ} \mathrm{C}\end{array}$} & \multirow{3}{*}{ A } & \multirow{3}{*}{15} & 1 & 475 \\
\hline & & & 9 & 675 \\
\hline & & & 17 & 825 \\
\hline \multirow{4}{*}{$\begin{array}{l}\text { Quenching in } \\
\text { water, } 27^{\circ} \mathrm{C}\end{array}$} & \multirow{4}{*}{ B } & \multirow{4}{*}{30} & 3 & 475 \\
\hline & & & 11 & 675 \\
\hline & & & 19 & 825 \\
\hline & & & 25 & 900 \\
\hline \multirow{3}{*}{$\begin{array}{l}\text { Quenching in } \\
\text { water, } 27^{\circ} \mathrm{C}\end{array}$} & \multirow{3}{*}{$\mathrm{C}$} & \multirow{3}{*}{45} & 5 & 475 \\
\hline & & & 13 & 675 \\
\hline & & & 21 & 825 \\
\hline \multirow{3}{*}{$\begin{array}{l}\text { Quenching in } \\
\text { water, } 27^{\circ} \mathrm{C}\end{array}$} & \multirow{3}{*}{$\mathrm{D}$} & \multirow{3}{*}{60} & 7 & 475 \\
\hline & & & 15 & 675 \\
\hline & & & 23 & 825 \\
\hline \multirow{3}{*}{ Normalizing in air } & \multirow{3}{*}{ E } & \multirow{3}{*}{15} & 2 & 475 \\
\hline & & & 10 & 675 \\
\hline & & & 18 & 825 \\
\hline \multirow{4}{*}{ Normalizing in air } & \multirow{4}{*}{$\mathrm{F}$} & \multirow{4}{*}{30} & 4 & 475 \\
\hline & & & 12 & 675 \\
\hline & & & 20 & 825 \\
\hline & & & 26 & 900 \\
\hline \multirow{3}{*}{ Normalizing in air } & \multirow{3}{*}{ G } & \multirow{3}{*}{45} & 6 & 475 \\
\hline & & & 14 & 675 \\
\hline & & & 22 & 825 \\
\hline \multirow{3}{*}{ Normalizing in air } & \multirow{3}{*}{$\mathrm{H}$} & \multirow{3}{*}{60} & 8 & 475 \\
\hline & & & 16 & 675 \\
\hline & & & 24 & 825 \\
\hline
\end{tabular}

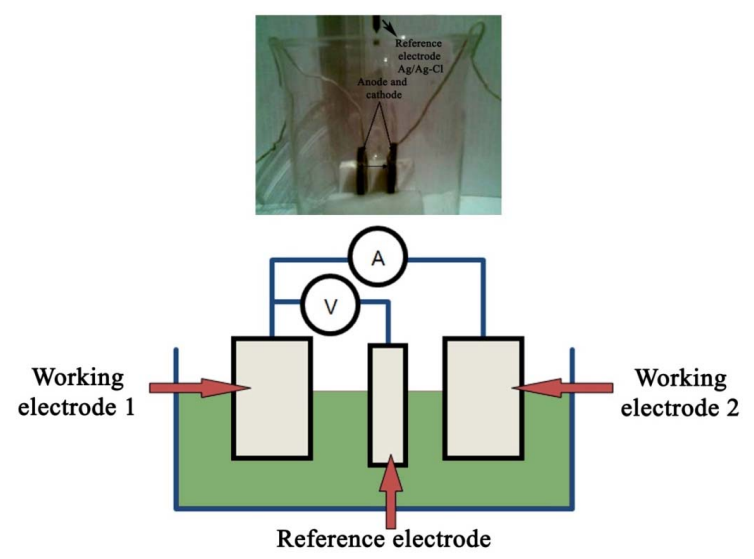

Figure 1. Schematic of the location of the alloy and electrodes in the container filled with artificial seawater.

\section{Results and Discussion}

The microstructure is characterized by metallographic techniques and is found to consist of $\alpha$-phase, retained $\beta$-phase and numerous $K$-phases. The microstructures of the specimens before and after heat treatment are shown in Figures $\mathbf{2}$ and 3, respectively. In the cast alloy, $\beta$ phase transforms to $\alpha$ phase together with some lamellar $K_{I I I}$ at grain boundaries and globular star shape $K_{I I}$ precipitates. $K_{I I I}$ is $\mathrm{Ni}$ based (usually AlNi) and $K_{I I}$ and $K_{I V}$ are a combination of $\mathrm{Fe}$ and $\mathrm{Al}$ was always emerging as $\mathrm{Fe}_{3} \mathrm{Al}$ compound in the microstructure (see Figure 2).

Normalizing at a lower temperature causes formation of fine Fe rich $K_{I V}$ within the grains. However, if the cooling was not slow enough, some of the high temperature $\beta$ was retained as a martensitic structure. The martensite was then transformed into a very fine mixture of $\alpha$ and $K$ phases, with $\mathrm{NiAl}$ precipitates, referred to as tempered martensite (see Figure 3).

$\mathrm{XRD}$ analysis was performed in one of the specimens normalized at $900^{\circ} \mathrm{C}$ showing $\mathrm{Cu}$-rich $\alpha$ phase was formed along with $K_{I I I}$ or $K_{I V}$ in the matrix (Figure 4). It was observed that with increasing the normalizing temperature $\beta$ phase increased dramatically and eutectoid transformation products together with $K$ phases were decreased. This may in turn affect the reaction products with the corrosive environment. Figure 5 shows the microstructure of the alloy after normalizing at $900^{\circ} \mathrm{C}$ which $K_{I I I}$ and $K_{I V}$ phases were formed in the matrix as well as presenting retained $\beta$ phase.

However, the quenched alloy contained Widmanstatten and $\alpha$ phase in a matrix of martensite. When the specimens were cooled in air more Widmanstatten and $\alpha$ have formed in the matrix. Additionally, the specimen held in longer time at the heat treatment temperature and quenched in water contained martensite and bainite plus fine eutectoid surrounding the Widmanstatten and $\alpha$. For 

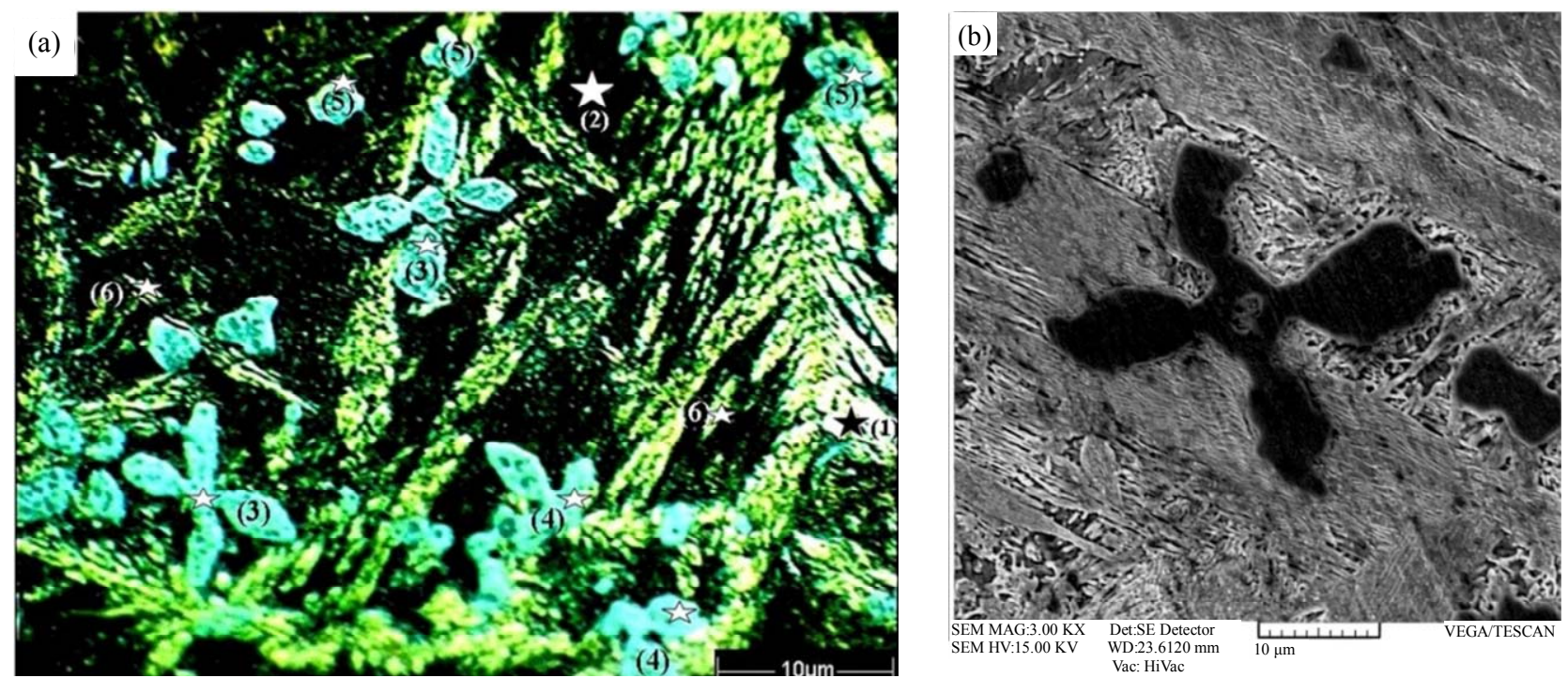

Figure 2. (a) Microstructure of the alloy before heat treatment and corrosion tests and (b) star shape intermetallic at the centre of the non-treated specimen.

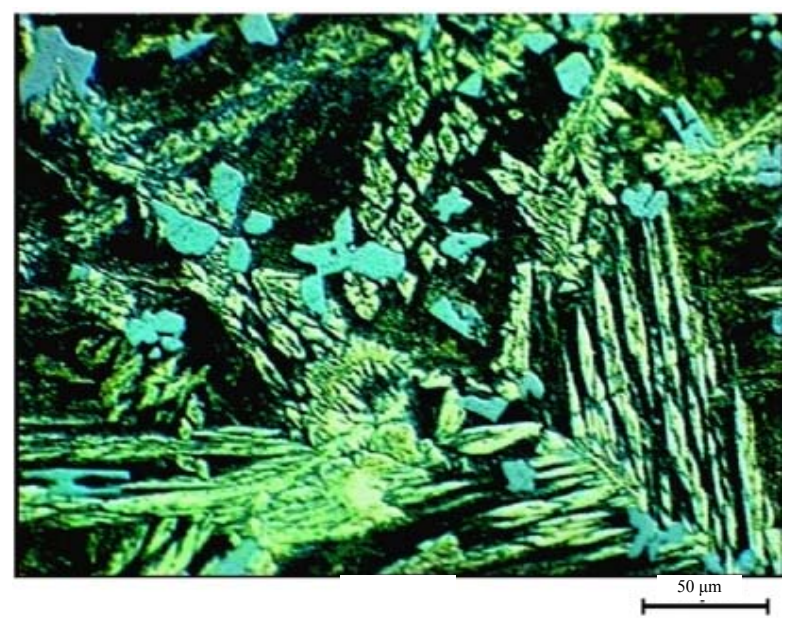

(a)

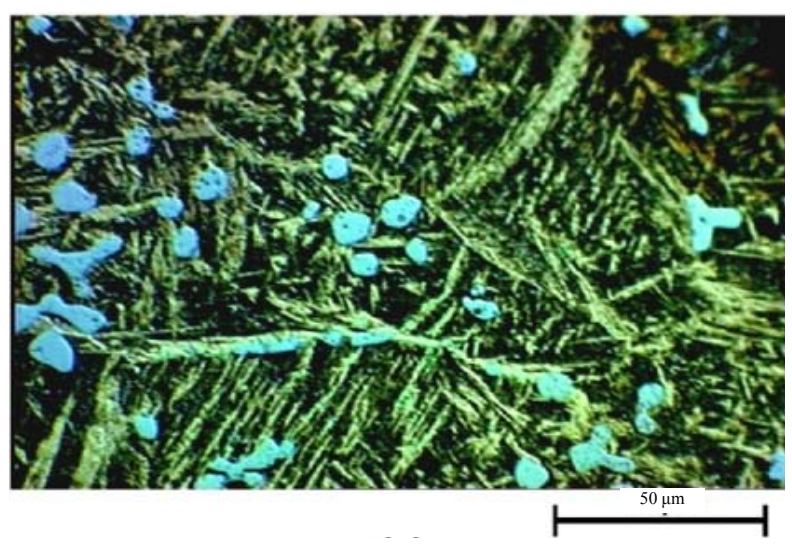

(c)

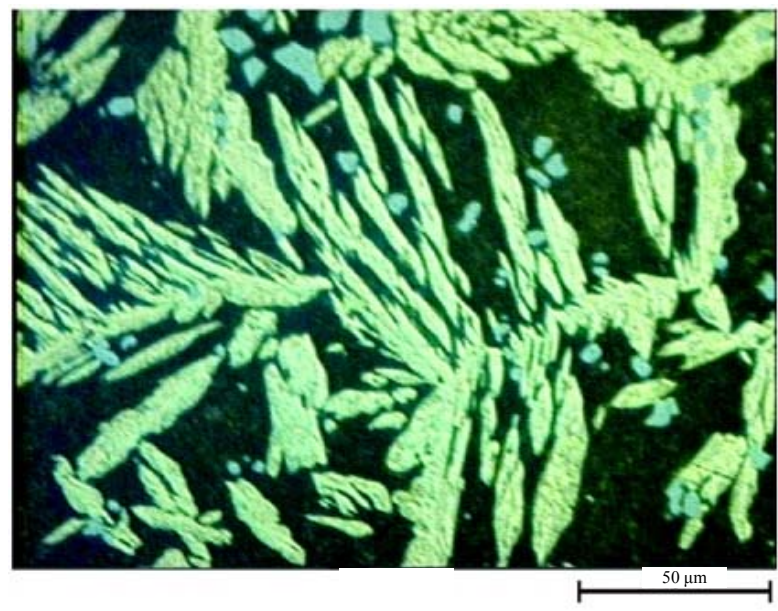

(b)

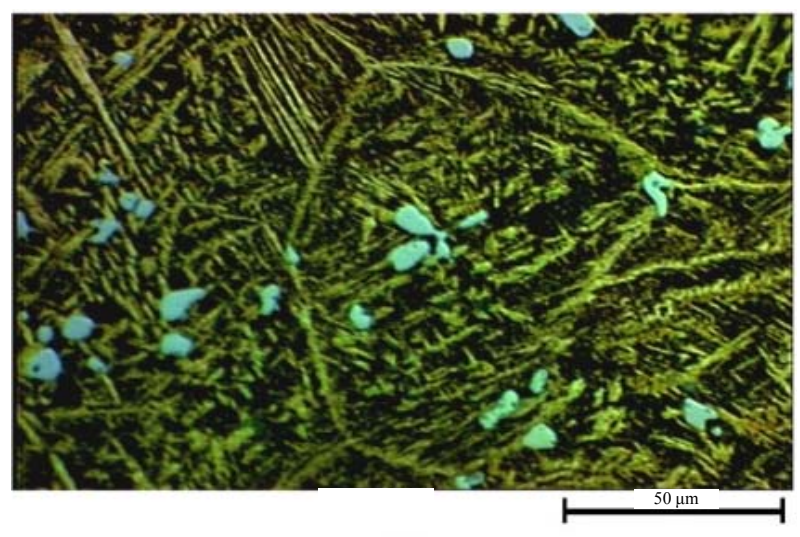

(d)

Figure 3. Microstructure of the alloy after normalizing at (a) 475; (b) 675 ; (c) 825 and (d) $900^{\circ} \mathrm{C}$ for 30 min. 


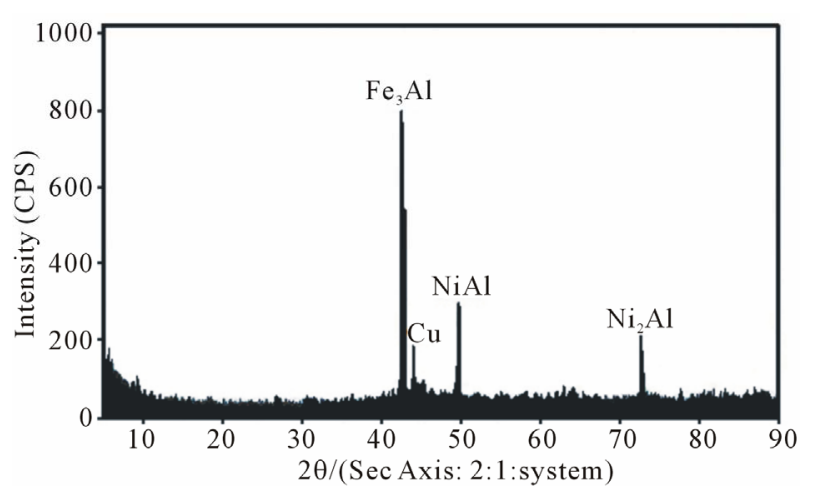

Figure 4. X-ray diffraction from the specimen normalized at $900^{\circ} \mathrm{C}$.

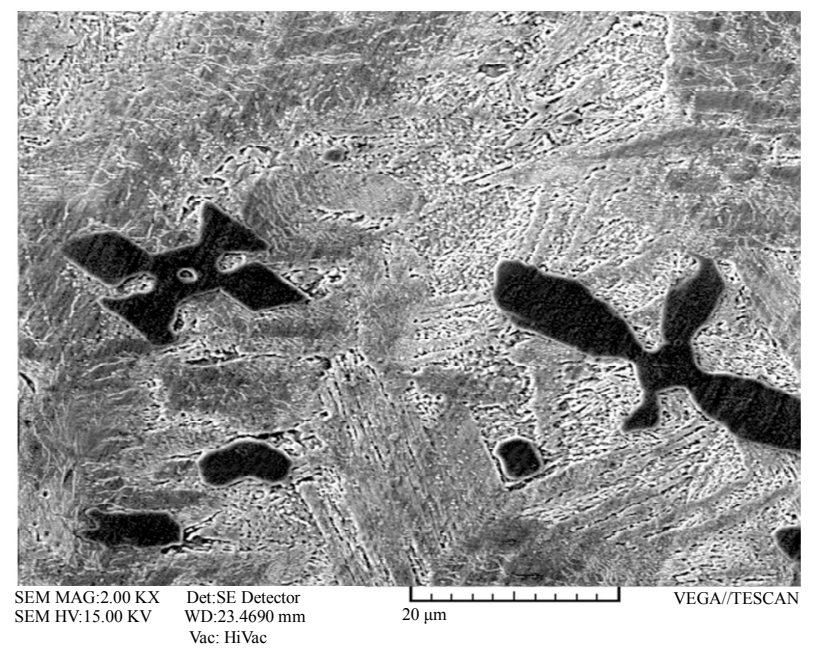

Figure 5. Microstructure of the alloy normalized at $900^{\circ} \mathrm{C}$.

example in the specimen of group A in Table 3, tempering transformed martensite and bainite to a fine eutectoid. As it is seen in Figure 5, when the alloy was cooled in air, Widmanstatten and $\alpha$ phase, eutectoid and traces of bainite and martensite were obviously appeared in the microstructure. However, when the specimens were normalized at $900^{\circ} \mathrm{C}$, some of $\beta$ phase transformed into $\beta^{\prime}$ phase, and the other transformed into lamellar $\alpha$ and $K$ intermetallic phases distributing along the boundaries of the alloy. Although martensitic transformation happened during quenching, the microstructure of the alloy still consisted of $\alpha, \beta^{\prime}$ and $K$ phases. It was seen that the volume fraction of $\beta^{\prime}$ phase increased in the quenched specimens due to the dissolution of both $\alpha$ and $K$ phases.

\subsection{Linear Polarization Test}

Figure 6 shows the result of potentiodynamic polarization for the alloy as a function of heat treatment cycle, measured using linear polarization method. The results show a significant similarity in the polarization curves of the specimens heat treated at different heating cycles. It is noted that for the specimen normalized at $675^{\circ} \mathrm{C}$ for 45 min and then cooled in air (code 14) the polarization resistance was higher than other specimens and its related curve in the polarization diagram shifted to the left side. The results shown in Figure 6 may reflect that the alloy exhibits a higher protective phases in the matrix in the corrosive environment. Although the effect of microstructural difference between intermetallic compounds, primary phases and grain boundary on the corrosion behavior of the metal is not yet well established, the greater polarization resistance of the specimen with the mentioned condition may indicate that some phases are more resistant to corrosion.

The faster cathodic reaction, resulting from a microstructure with less corrosive phases, was established to associate with the reaction of $\mathrm{Fe}$ and $\mathrm{Cu}$ atoms with other elements in imperfection sites introduced by the heat treatment cycles. From another point of view, in the alloy subjected to air cooling from high temperatures, a higher dislocation density is anticipated, causing a raise in cathodic reaction rate [22]. Similarly, for the coarsened grained alloy heat treated in lower temperature, the coarsening of Widmanstatten phase produces lower dislocation density, leading to a reduction in cathodic reaction rate and a superior polarization resistance. Furthermore, the presence of Fe showed improvements in corrosion behavior of the alloy. Williams and Komp [23] have reported that an increase in $\mathrm{Cu}$ content affected the cathodic polarization behavior in such a way as to reduce the rate of the cathodic reaction in the corrosion process, thereby decreasing corrosion rate. The polarization resistances of the heat treated specimens, however, were higher than that of the non-heat treated alloy. It is obvious that higher $\mathrm{Al}$ and $\mathrm{Cu}$ contents in the alloy provided by impoverishing some phases offer the beneficial effect on the corrosion resistance as the heat treated alloy (code 14) exhibits greater protective layers on the surface.

As it was seen, an especial heat treatment can affect the results of linear polarization in a way that some of them showed high electronic and ionic resistance during the immersion, indicating the products of the corrosion system are more stable and protective. Analysis of the linear polarization curves revealed active-passive behavior for the alloy. After the passive range, rapid increases of current density occurred and passive layer destruction proceeds and following transition into pitting corrosion region is seen for the alloy heat treated with the quenching process. Before this transition, some ephemeral pits formed but were rapidly re-passivated. The main corrosion in this case can be pitting. In contrast, for the substrate subjected to normalizing, $i_{\text {corr }}$ increased smoothly with increasing potential and the usual active-passive transition was not appeared. This can be attributed to 


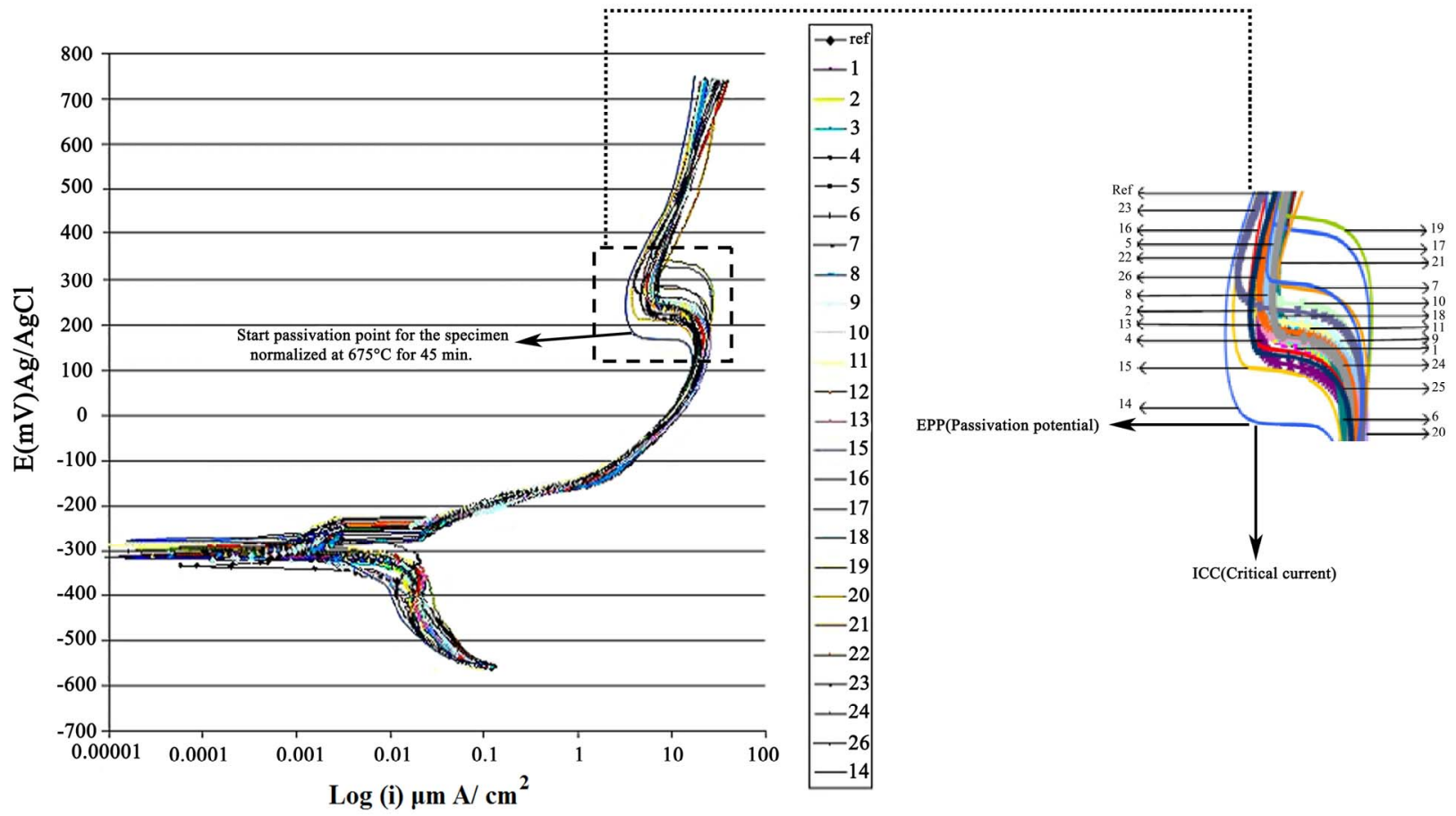

Figure 6. Linear polarization test results for the alloy heat treated in different conditions.

selective corrosion. It also conceived that commence of passivation was from lower potentials indicating superior specimens for preventing corrosion in artificial seawater solution. In addition, the normalized specimens exhibited more extended passive behavior in comparison with the quenched specimens. It was also found that the $K$ phases were not attacked, indicating that they were cathodic with respect to the $\mathrm{Cu}$-rich $\alpha$ phase. The continued dissolution of $\alpha$ phase is expected to result in the eventual loss of the $K$ intermetallic compounds. However, it was reported that the corrosion of the alloy in artificial seawater is basically galvanic in nature [24,25]. The $\mathrm{Cu}$-rich phase was selectively attacked at the interfaces with the intermetallic phases in artificial seawater. Cavitations resulted in a rough surface, containing large size cavities, ductile tearing and grain boundary attack. Microcracks of about $12 \mathrm{~mm}$ in length were observed in $\mathrm{Cu}$ rich phase adjacent to intermetallic phases. It is believed that selective phase corrosion and cavitation stresses were the main cause of cracking [26]. However, a big doubt about the mechanism of corrosion in the specimens has spurred this investigation to be extended. Hence, extracted results of potentiodynamic curves by Tafel extrapolation are reported in Figure 7. The main results derived from the performed potentiodynamic tests are repeatedly higher corrosion resistance of the normalized specimens compared to the cast and quenched specimens. Noticeably, the superior specimen made up a balance between low current density, low potential and high passive range.
When martensite is considered, a high energy level seems to be associated with its resulting microstructure which can significantly affect its corresponding electrochemical behavior. Due to this, it is expected a higher susceptibility to corrosion than those other examined heat-treated specimens. Nonetheless, both martensite structure and volume fraction of dendritic $\mathrm{Cu}$-rich phase were strongly affected by the applied cooling rate intrinsically in each process.

The effect of heat treating cycles on the polarization characteristics of the alloy depends on the composition of the alloy. With the presence of $\mathrm{Cu}$ and $\mathrm{Al}$ in the microstructure the polarization has been significantly modified via dissolving the $\mathrm{Cu}$ and $\mathrm{Al}$ and increasing the $\mathrm{Cu}$ content in solid solution. In the alloy, the dissolution of the $\mathrm{Ni}$ and $\mathrm{Cu}$ rich phases increased the $\mathrm{Al}$ contents in solid solution, but did not significantly enhances the passivation power of the surface of the alloy. The similarity between the polarization curve for the reference specimen and those heat treated seems to support this point. To substantiate the point, the polarization curve for a reference specimen was acquired. By comparison, it can be seen that the curve for the reference specimen and the heat treated specimens were very similar. This point is clearer in the peak current density and the corresponding potential, and also the passive current density, indicating that the anodic polarization behavior of the alloy in the aqueous solution was fundamentally controlled by $\mathrm{Cu}-$ and Al-containing phases. Nonetheless, the effect of the 


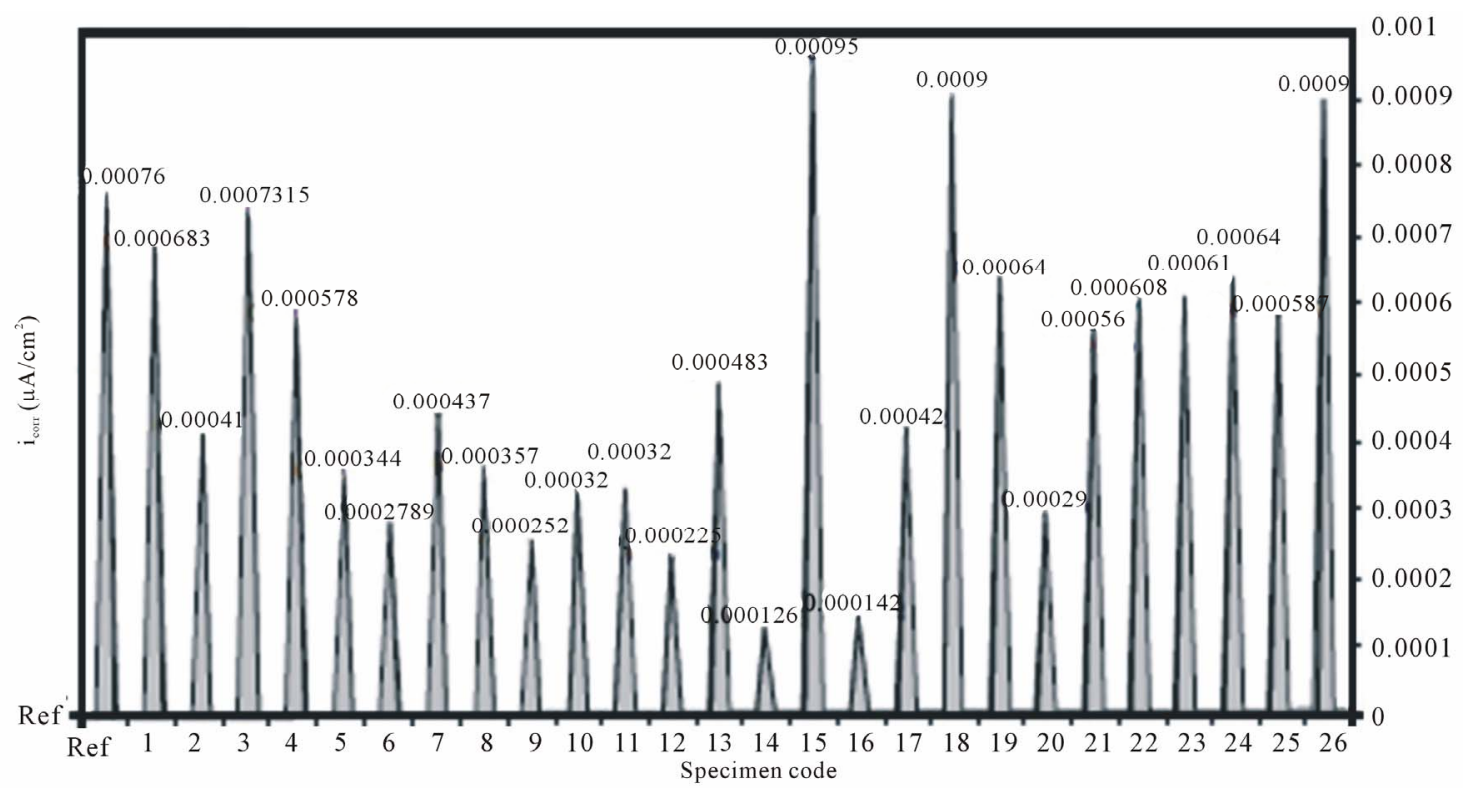

Figure 7. Various corrosion current rate after polarization test.

heat treatment cycles was obvious by a lower corrosion potential and an inflexion at around $600 \mathrm{mV}$ (SCE) in the polarization curve, indicating the preferential dissolution of some elements beyond that potential. It should be mentioned that the differences in Tafel results are attributed to differences in the surface film composition which, in turn, arise from the compositional differences between the alloys heat treated in different cycles.

The importance of the effect of the microstructures on the corrosion behavior of the alloy was a significant indication of the influence of heat treatment cycles on the surface morphology evolution. For instance, the signs of corrosion were observed at a very early stage with roughening of the $K_{I}$ phase. Local attack, however, at the $\alpha / K_{I}$ boundaries began to take place after six days (see Figure 8).

With increasing the immersion time, corrosion products began to appear in $\alpha$ and $\beta$ matrix, but the corrosion attack was much more rigorous at the active $K$ phases and $\alpha / K$ boundaries. This attack was signaled delineation of grain boundaries at the first stages of corrosion. Moreover, some corrosion products began to appear at the grain boundaries of the specimens normalized at $675^{\circ} \mathrm{C}$. Normalizing process reduced the chance of forming local galvanic cells which might exist between different phases, and improved the corrosion resistance of the alloy. The calculated corrosion potential $E_{\text {corr }}$ for all specimens indicated a close range between the results leading to an average estimation of about $-305 / 66 \mathrm{mv}$. For easing the corrosion analysis, some specimens (ref., $3,5,6,12,14,18,20,25$ and 26) with highest and lowest $i_{\text {corr }}$ were chosen for electrochemical impedance test from the groups shown in Table 3. Each experiment was carried out two times in order to produce more reliable results. The solution resistance $\left(R_{S}\right)$ and the polarization resistance or charge transfer resistance $\left(R_{p}\right)$ were derived using the equivalent circuit model as shown in Figure 9.

As it is seen in the model, $R_{1}$ is equivalent to $R_{s}$. Figure 10 shows the Nyquist plots obtained from AC impedance (EIS) measurement for the specimens immersed

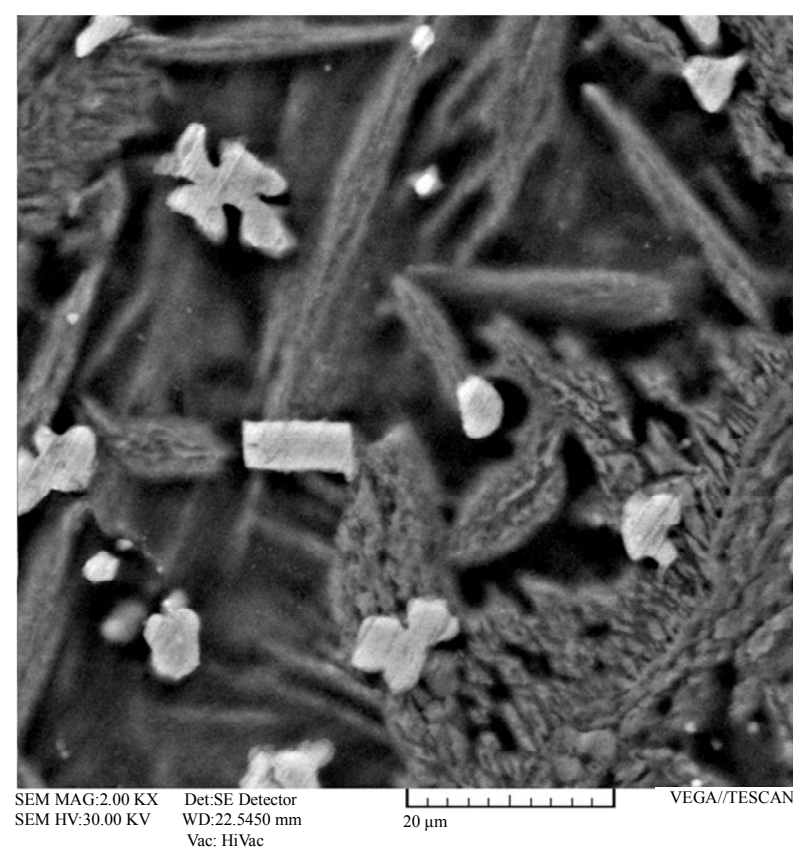

Figure 8. SEM micrographs showing evolution of damage morphology in the specimen normalized at $675^{\circ} \mathrm{C}$ and immersed in artificial seawater for six days. 
in artificial seawater. For plotting the diagrams the corrosion rate $\left(C_{R}\right)$ and corrosion current density $\left(i_{\text {Corr }}\right)$ were calculated from Equations (1) and (2) in a code written in the software.

$$
\begin{gathered}
i_{\text {Corr }}=\frac{1}{46 R_{p}}\left(\frac{\mathrm{mA}}{\mathrm{cm}^{2}}\right) \\
C_{R}=1300 \times \frac{M \cdot i_{\text {Corr }}}{n \cdot D}(\mathrm{mpy})
\end{gathered}
$$

where, $D, M$ and $n$ are density $\left(\mathrm{g} / \mathrm{cm}^{3}\right)$, molecular weight $(\mathrm{g} / \mathrm{mol})$ and valence of the alloy, respectively. As can be seen from Figure 10, different behavior can be observed considering all parameters involved in the test. The amount of the polarization resistance taken from the EIS measurement in the alloy depends on the history of heat treatment of the specimens. For instance, $R_{P}$ value of the normalized specimens at $675^{\circ} \mathrm{C}$ enhanced in comparison with the quenched specimens.

By comparing the results obtained from different specimens, it can be seen that the Nyquist plots have small polarization resistances at the open circuit potentials. This means that charge transfer process controls the corrosion behavior of the specimens in artificial seawater. The Nyquist plot also clearly shows that the quenching process caused displacing in the left side of the Nyquist plots. It means that the quenching treatment led to a decrease in the impedance of the specimens. However, it is interesting to note that, normalizing the specimens changes the diameter of the semicircles in the Nyquist plots indicating an increase in the value of polarization resistance. Based on the results from the EIS measurement, it can be stated that the normalized alloy (specimen 14) showed the highest corrosion resistance, $R_{p}$, compared to other specimens. It should also declare that insignificant changes occurred in the Nyquist plots of some substrates. This might be attributed to the effect of microstructure of the heat treated alloys for absorbing artificial seawater due to dissociation into anions and cations and their involvement to the electrochemical process with increasing the corrosion rate [27].

Among the specimens the corrosion rate in the normalized alloy decreased to around $19 \%$. This result can probably be attributed to the supply of oxygen for the $\mathrm{Al}$ passivation by artificial seawater and formation of a com-

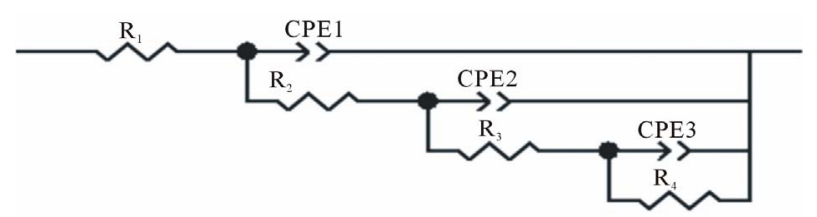

Figure 9. Equivalent electrical circuit model used to derive $\boldsymbol{R}_{S}$ and $\boldsymbol{R}_{p}$. pact thin layer of $\mathrm{Al}$ oxide on its surface and finally reaching to Warburg impedance. However, in the normalizing process if the temperature reached to $900^{\circ} \mathrm{C}$ the alloy lost its protection against the corrosive environment. This can be associated with the dissolution of the oxide layer and $\mathrm{Cu}$-rich phase as anodic walls during the corrosion process. The Warburg impedance was created with diffusion process. As the impedance depends on the frequency of the potential perturbation, at high frequencies the Warburg impedance was small since diffusing reactants did not have to move very far. At low frequencies the reactants had to diffuse farther, increasing the Warburg-impedance. On the Nyquist plot the Warburg impedance appeared as a diagonal line with a slope of $45^{\circ}$ and on the Bode plot, the Warburg impedance exhibited a phase shift of $45^{\circ}$. At the higher normalizing temperature passivation layer resistance had faced with diffusional phenomenon. It means that another resistance circuit, a new one $\left(Z_{w}\right)$, added to the electrical circuit. This can be shown in the electrical circuit with $R_{p}$. It is probable the initial time taken to achieve the stabilized potential is associated with the dissolution and conversion of the thermal oxide films. The change from more positive potentials exhibited by the oxides to more negative potentials is due to the changes in the surface films. This process relies on the rate of mass transport for the chloride ion and the cuprous dichloride complex, both of which are engaged in the dissolution of the cuprous oxide. The passivation of the alloy was based on the oxidation of aluminum. It is believed that the aluminum has an enormous affinity for oxygen than other solutes like $\mathrm{Cu}$ and always $\mathrm{Al}_{2} \mathrm{O}_{3}$ is approximately ten times more stable than $\mathrm{Cu}_{2} \mathrm{O}$ [5]. However, a single equivalent circuit can be applied where $R_{s}$ is the solution resistance which in Bode diagram is expressed in a high frequency limit $(\mathrm{F}>1$ $\mathrm{Hz}), R_{I}$ is the passive oxide film resistance and ZCPE is the constant-phase element for the oxide film. On the other hand, as other alternative a complex equivalent circuit consisted with $R_{s}$ also corresponding to the solution resistance, $R_{1}$ and $R_{2}$ are the resistances of the porous and barrier layers, respectively [28-31]. For the substrate, thermal oxidation was based on a rapid initial production of $\mathrm{Cu}_{2} \mathrm{O}$ at the alloy/oxide interface due to the depletion of $\mathrm{Cu}$. Alumina consequently formed as a protective oxide which was extremely resistant to the passage of cuprous cations which can no longer enter in the layer of cuprous oxide. Providing higher aluminium content by an appropriate thermal cycle can lead to the greater corrosion resistance due to the protective alumina film.

\subsection{Electrochemical Noise Measurements}

Electrochemical noise analysis shown in Figure 11 confirmed that the type of corrosion in the specimens nor- 

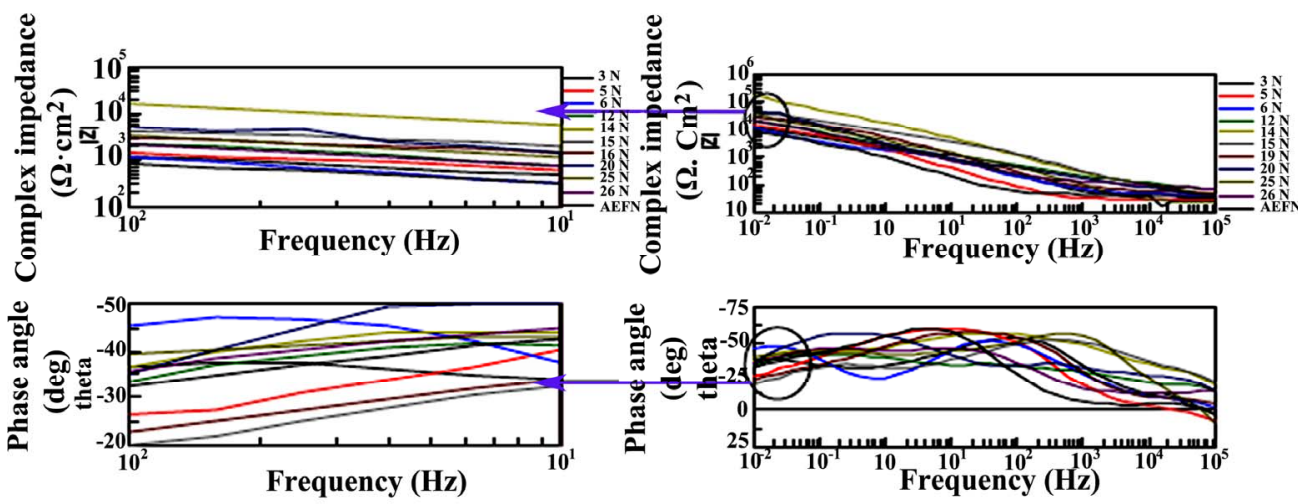

(a)

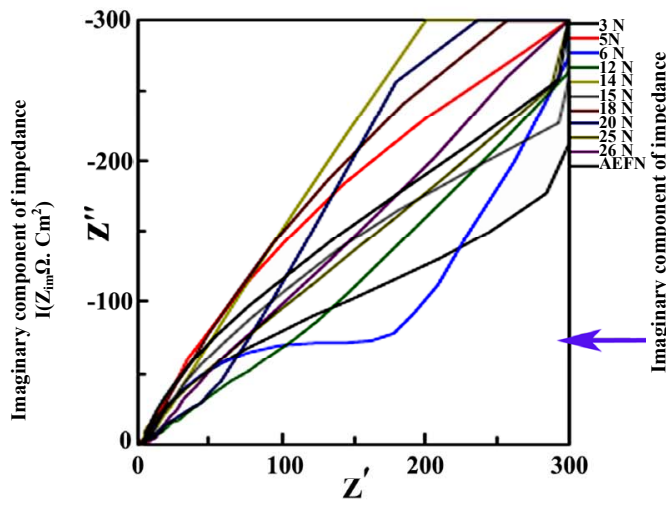

Real component of impedance $\left(\mathrm{Z}_{\text {re }} \mathbf{\Omega} . \mathrm{Cm}^{2}\right)$

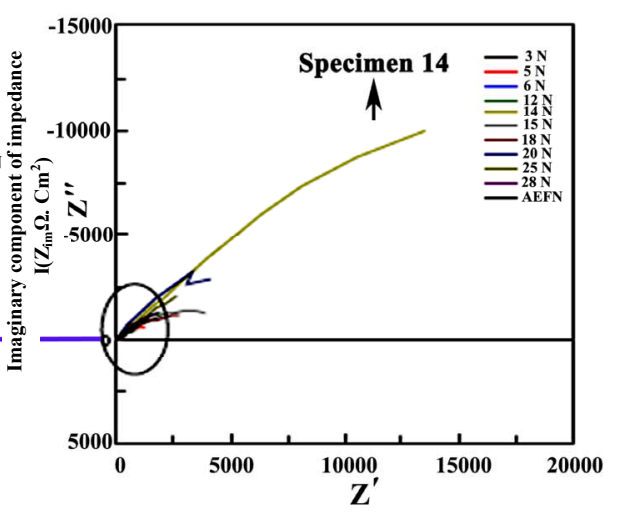

Real component of impedance $\left(\mathrm{Zre}_{\mathrm{re}} \mathbf{\Omega} . \mathrm{Cm}^{2}\right)$

(b)

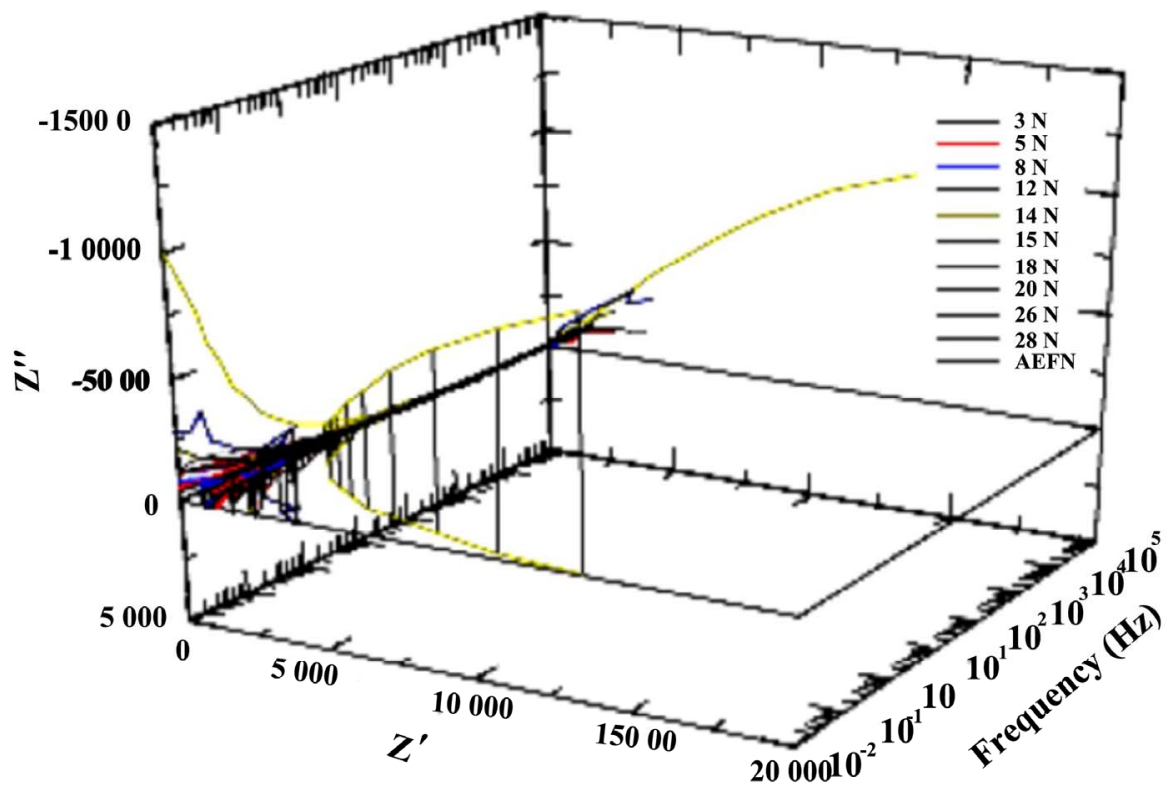

(c)

Figure 10. (a) Bode plots, (b) Nyquist plots of the specimens tested in artificial seawater based on the heat treatment histories, obtained from electrochemical impedance spectroscopy test and (c) three dimensional plot relating all parameters involved in the test. 
malized at $675^{\circ} \mathrm{C}$ was selective and pitting corrosions. For the normalized specimens, it was observed that after 20 days immersing in artificial seawater there was not any considerable change in current and potential noises.

After reaching to 40 days, a slight drop in potential to negative volumes was observed. This was attributed to the nucleation of semi-stable pits on the passive surface in selective corrosion mechanism. Transmuted noises from high frequencies with low interval in current noise indicated dealominification was the selective phase at the
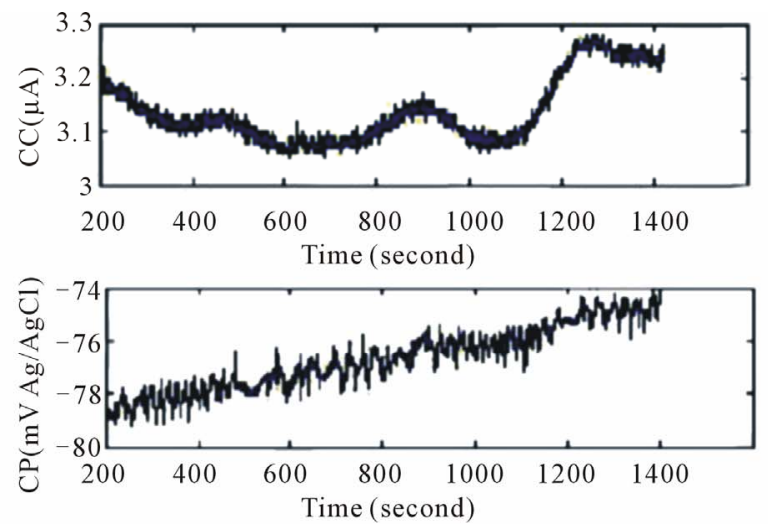

(a)
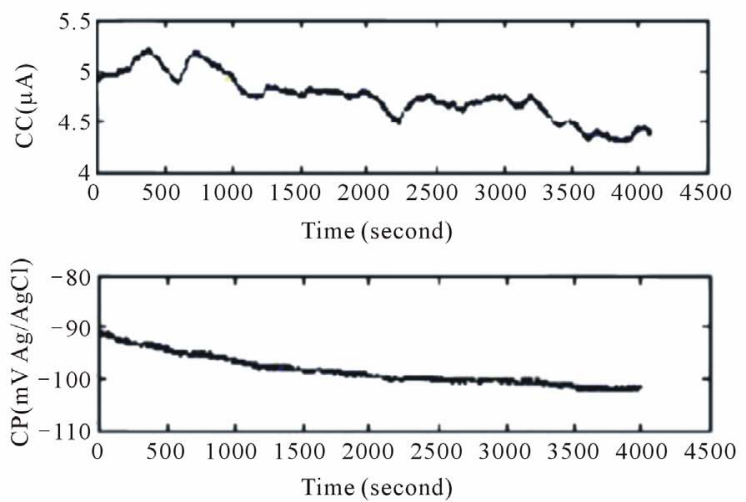

(c) primary stage of the corrosion process. After 50 days, alterations in noise were dramatically increased and the passive surface lost its ability to provide essential current for the selective corrosion. Consequently, after 75 days the current was extensively decreased. At this stage the possibility of forming unstable pits were minimized. However, a sharp drop in current was seen indicating a dissolution or consumption of $\mathrm{Ni}, \mathrm{Al}$ and $\mathrm{Fe}$ in the passive film. This phenomenon formed bubble shape corrosion products from $\mathrm{Cu}$ rich passive surface and increased
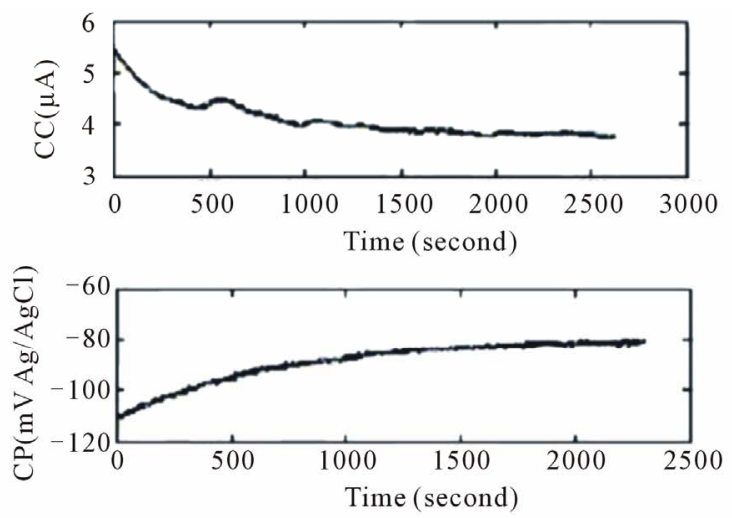

(b)
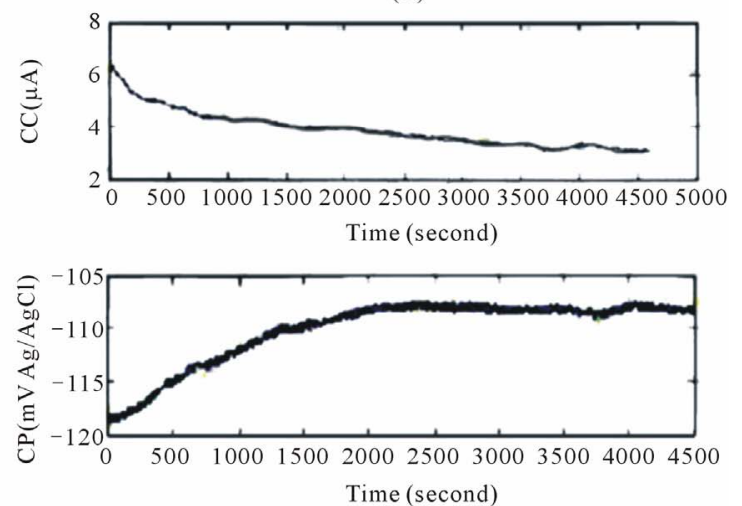

(d)
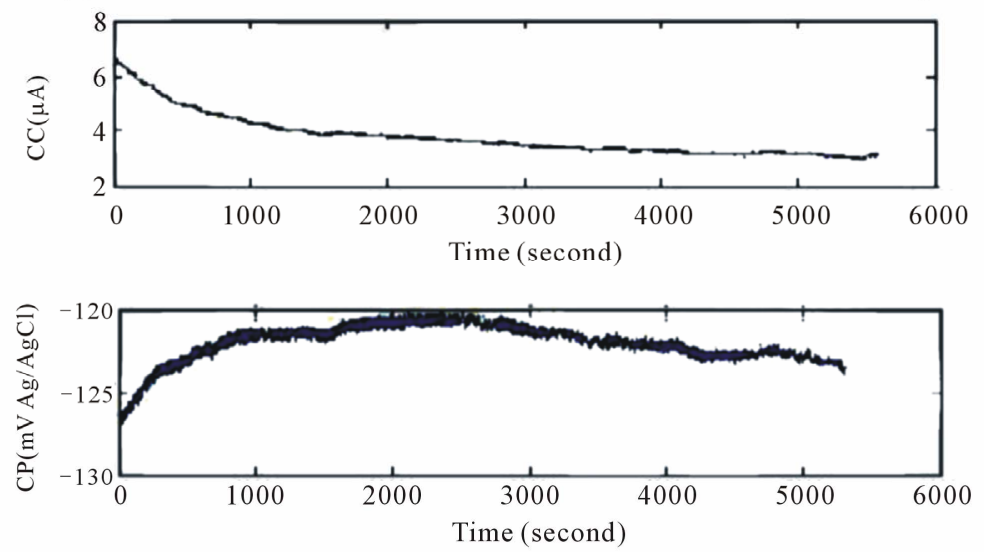

(e)

Figure 11. ZRA curves for the normalized ANB alloy after (a) 11 days; (b) 20 days; (c) 40 days; (d) 50 days and (d) 75 days. 
anodic areas. A comparison between different specimens shows dissimilar response in terms of potential and current via immersing days in ZRA test (Figure 12).

As it is seen in Figure 12, the highest value of potential $(-123 / 4631 \mathrm{mV})$ is for specimen 14 , the one normalized at $675^{\circ} \mathrm{C}$. The reference specimen also showed a current value of $6 / 148 \mu \mathrm{A}$, while specimen 14 shows the lowest current value of about $3 / 1348 \mu \mathrm{A}$ after 75 days immersing in artificial seawater. The results indicated that specimen 14 was heat treated in an optimum condition among other heat treated nickel-aluminum bronze specimens. In this view, lower corrosion Fe-base products were appeared in the specimen 14 . The anodic reaction in the retained $\beta$ matrix was lower than other phases in this specimen leaving the phase uncorroded. At $675^{\circ} \mathrm{C}$ of normalizing temperature, the temperature was not enough to increase the current corrosion while in other specimens, especially those normalized at $900^{\circ} \mathrm{C}$, the current corrosion increased. SEM image of the surface of the reference specimen after exposing to artificial seawater for 75 days is shown in Figure 13. In the alloy heat treated with quenching and normalizing processes some

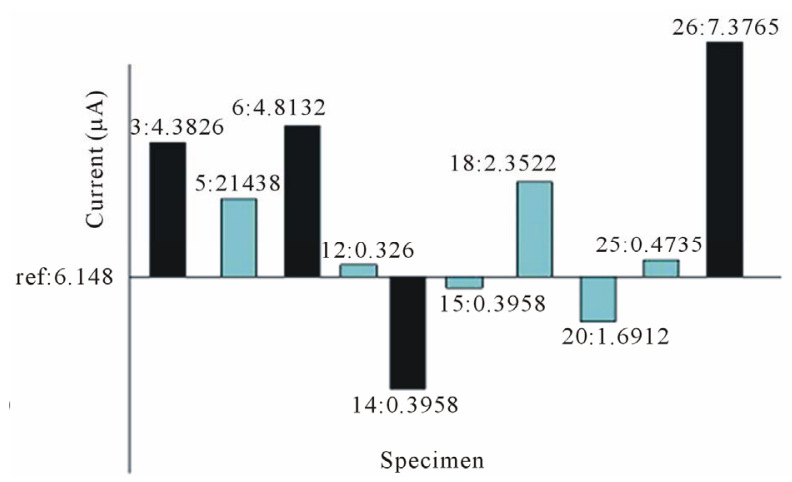

(a)

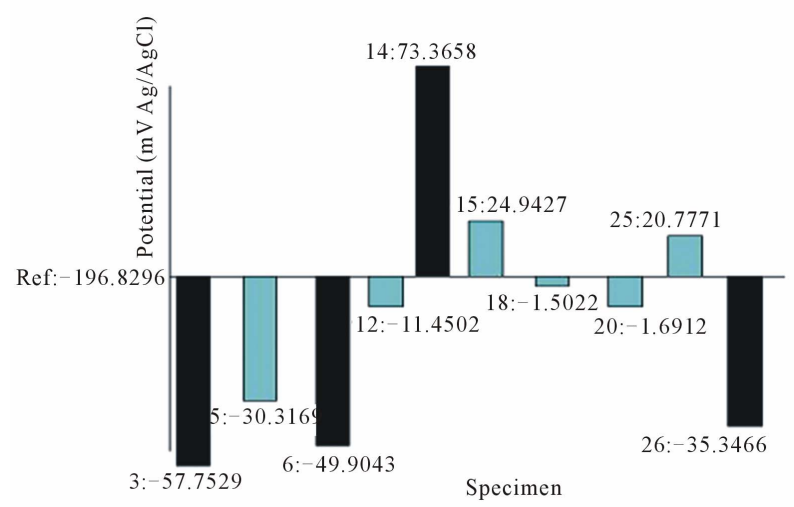

(b)

Figure 12. Comparison between current and potential of ZRA test for the specimens normalized and quenched at different temperatures for $\mathbf{4 5} \mathbf{~ m i n}$.

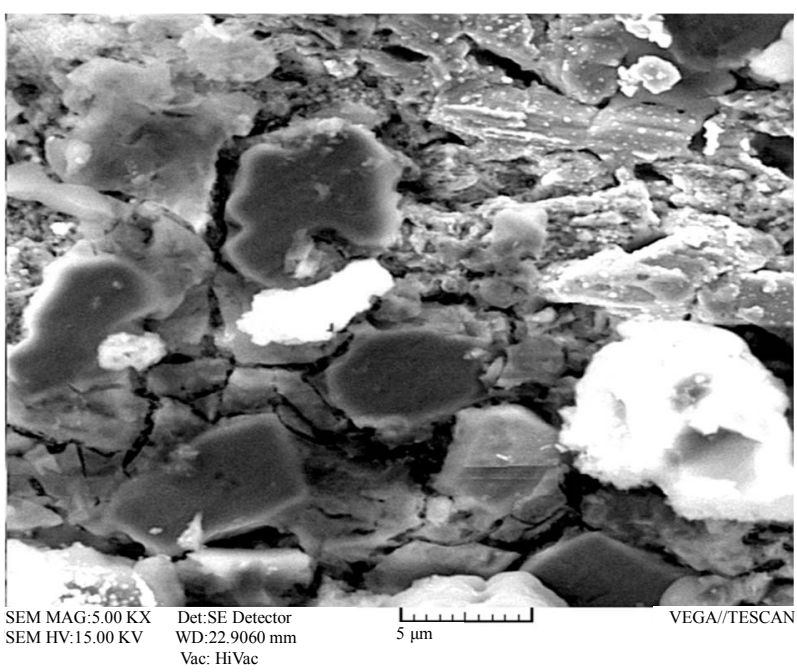

Figure 13. SEM images from the surface of reference specimen after exposing to artificial seawater for 75 days.

of the elements were dissolved in the passive layer making some parts more anodic than other parts. This prepares some local areas for aggressive pitting corrosion.

\section{Conclusions}

The influence of pre-heat treatment on the corrosion behavior of nickel-aluminum bronze was investigated. The following results obtained from the present study can be drawn:

1) The normalized specimens exhibited significantly lower fractions of pits and better corrosion resistance to artificial seawater in comparison with quenched specimens. Superior specimen showed better corrosion resistance in both short and long term corrosion tests, even better than reference specimen.

2) The corrosion rate of the alloy was dependent on many parameters including the nature of the surface films, the heat treatment process, the alloy composition and the time of immersion in artificial seawater.

Polarization plots showed that the Warburg impedance occurred in the passive layer of the specimen normalized at $675^{\circ} \mathrm{C}$. The corrosion resistance of the alloy benefited from the microstructure resulted from pre-heat treatment process.

\section{REFERENCES}

[1] R. C. Barik, J. A. Wharton, R. J. K. Wood, K. S. Tan and K. R. Stokes, "Erosion and Erosion-Corrosion Performance of Cast and Thermally Sprayed Nickel-Aluminium Bronze," Wear, Vol. 259, 2005, pp. 230-242.

doi:10.1016/j.wear.2005.02.033

[2] A. Al-Hashem and W. Riad, "The Role of Microstructure of Nickel-Aluminium-Bronze Alloy on its Cavitation Corrosion Behavior in Natural Seawater," Materials 
Characterization, Vol. 48, 2002, pp. 37-41. doi:10.1016/S1044-5803(02)00196-1

[3] F. Hasan, J. Iqbal and N. Ridley, "Microstructure of Ascast Aluminum Bronze Containing Iron," Materials Science Technology, Vol. 1, 1985, p. 312.

[4] F. Hasan, A. Jahanafrooz, G. W. Lorimer and N. Ridley, "The Morphology, Crystallography, and Chemistry of Phases in As-cast Nickel-Aluminum-Bronze," Metallurgical Transactions A, Vol. 13A, 1982, p. 1337. doi:10.1007/BF02642870

[5] J. A. Wharton, R. C. Brik, G. Kear, R. J. K. Wood, K. R. Stokes and F. C. Walsh, "The Corrosion of Nickel-Aluminum Bronze in Seawater," Corrosion Science, Vol. 47, 2005, pp. 3336-3367. doi:10.1016/j.corsci.2005.05.053

[6] J. A. Wharton and K. R. Stokes, "The Influence of Nickel-Aluminum Bronze Microstructure and Crevice Solution on the Initiation of Crevice Corrosion," Electrochimica Acta, Vol. 53, 2008, pp. 2463-2473. doi:10.1016/j.electacta.2007.10.047

[7] M. D. Fuller, S. Swaminathan, A. P. Zhilyaev and T. R. Mcnelley, "Microstructural Transformations and Mechanical Properties of Cast NiAl Bronze: Effects of Fusion Welding and Friction Stir Processing," Materials Science and Engineering A, Vol. 463, 2007, pp. 128-137. doi:10.1016/j.msea.2006.07.157

[8] H. S. Campbell, "Aluminium Bronze Corrosion Resistance Guide," Publication 80, Copper Development Association, UK, July 1981, pp. 1-27.

[9] Z. Charlws and J. Ferrara Robert, "Sea Water Corrosion of Nickel-Aluminum Bronze," Transactions of the American Foundrymen's Society, Vol. 82, 1974, pp. 71-78.

[10] R.-P. Chen, Z.-Q. Liang, W. W. Zhang, D.-T. Zhang, Z.-Q. Luo and Y.-Y. Li, "Effect of Heat Treatment on Microstructure and Properties of Hot-Extruded Nickel-Aluminum Bronze," Transactions of Nonferrous Metals Society of China, Vol. 17, 2007, pp. 1254-1258. doi:10.1016/S1003-6326(07)60258-1

[11] A. Schussler and H. E. Exner, "The Corrosion of Nickel-Aluminium Bronzes in Seawater-I. Protective Layer Formation and the Passivation Mechanism," Corrosion Science, Vol. 34, 1993, p. 1793. doi:10.1016/0010-938X(93)90017-B

[12] H. Meigh, "Cast and Wrought Aluminium Bronzes-Properties," Processes and Structure, 1st Edition, IOM Communications, 2000.

[13] F. L. LaQue, "Marine Corrosion," Wiley, New York, 1975.

[14] J. C. Rowlands, "Studies of the Preferential Phase Corrosion of Cast Nickel Aluminium Bronze in Seawater," Proceeding of 8th International Congress of Metallic Corrosion, 1981, p. 1346.

[15] G. Kear, B. D. Barker, K. R. Stokes and F. C. Walsh, "Electrochemical Corrosion of Unalloyed Copper in Chloride Media-A Critical Review," Corrosion Science,
Vol. 47, 2004, p. 1694. doi:10.1016/j.corsci.2004.08.013

[16] G. Kear, B. D. Barker, K. R. Stokes and F. C. Walsh, "Electrochemical Corrosion Behaviour of $90-10 \mathrm{Cu}-\mathrm{Ni}$ Alloy in Chloride-Based Electrolytes," Journal of Applied Electrochemistry, Vol. 34, 2004, p. 659. doi:10.1023/B:JACH.0000031164.32520.58

[17] G. Kear, B. D. Barker and F. C. Walsh, "Electrochemistry of Non-Aged 90-10 Copper-Nickel Alloy (UNS C70610) as a Function of Fluid Flow Part 1: Cathodic and Anodic Characteristics," Electrochimica Acta, Vol. 52, No. 5, 2007, pp. 1889-1898. doi:10.1016/j.electacta.2006.07.054

[18] K. Habib, "Measurement of the a.c. Impedance of Aluminum Samples by Holographic Interferometry," Optics and Lasers in Engineering, Vol. 28, 1997, pp. 37-46. doi:10.1016/S0143-8166(96)00058-9

[19] K. Habib, "Zero Resistance Ammeter of Metallic Alloys in Aqueous Solutions," Optik-International Journal for Light and Electron Optics, Vol. 118, No. 6, 2007, pp. 296-301. doi:10.1016/j.ijleo.2006.03.023

[20] B. Zhao, J.-H. Li, R.-G. Hu, R.-G. Du and C.-J. Lin, "Study on the Corrosion Behavior of Reinforcing Steel in Cement Mortar by Electrochemical Noise Measurements," Electrochimica Acta, 2007, Vol. 52, pp. 3976-3984. doi:10.1016/j.electacta.2006.11.015

[21] R. A. Cottis, "Interpretation of Electrochemical Noise Data," NACE International Corrosion, Vol. 57, No. 3, 2009, pp. 65-23.

[22] H.-H. Huang, W.-T. Tsai and J.-T. Lee, "The Influences of Microstructure and Composition on the Electrochemical Behavior of a516 Steel Weldment," Corrosion Science, Vol. 36, No. 6, 1994, pp. 1027-1038. doi:10.1016/0010-938X(94)90201-1

[23] F. T. Cheng, K. H. Lo and H. C. Man, "An Electrochemical Study of the Crevice Corrosion Resistance of NiTi in Hanks' Solution," Journal of Alloys and Compounds, Vol. 437, 2007, pp. 322-328. doi:10.1016/i.jallcom.2006.07.127

[24] E. A. Culpan and R. Rose, "Corrosion Behaviour of Cast Nickel Aluminum Bronze in Sea Water," British Corrosion Journal, Vol. 14, No. 3, 1979, p. 160.

[25] G. W. Loriner, F. Hasan, J. Iqbal and N. Ridley, "Observation of Microstructure and Corrosion Behaviour of Some Aluminum Bronzes," British Corrosion Journal, Vol. 21, 1986, No. 4, pp. 244-247.

[26] A. Al-Hashem and W. Riad, "The Role of Microstructure of Nickel-Aluminium-Bronze Alloy on its Cavitation Corrosion Behavior in Natural Seawater," Materials Characterization, Vol. 48, No. 1, 2002, pp. 37-41. doi:10.1016/S1044-5803(02)00196-1

[27] H. Jafari, M. Hasbullah Idris, A. Ourdjini, H. Rahimi and B. Ghobadian, "EIS Study of Corrosion Behavior of Metallic Materials in Ethanol Blended Gasoline Containing Water as a Contaminant," Fuel, Vol. 90, No. 3, 2011, pp. 1181-1187. doi:10.1016/i.fuel.2010.12.010

[28] W. R. Osório, L. C. Peixoto, M. V. Canté and A. Garcia "Electrochemical Corrosion Characterization of Al-Ni Alloys in a Dilute Sodium Chloride Solution," Electro- 
chim Acta, Vol. 55, No. 13, 2010, pp. 4078-4085. doi:10.1016/j.electacta.2010.02.029

[29] W. R. Osório, L. C. Peixo, D. J. Moutinho, L. G. Gomes, I. L. Ferreira and A. Garcia, "Corrosion Resistance of Directionally Solidified Al-6Cu-1Si and Al-8Cu-3Si Alloys Castings," Materials and Design, Vol. 32, No. 7, 2011, pp. 3832-3837.

[30] W. R. Osório, L. C. Peixoto, M. V. Canté and A. Garcia, "Microstructure Features Affecting Mechanical Properties and Corrosion Behavior of a Hypoeutectic Al-Ni Alloy," Materials and Design, Vol. 31, No. 9, 2010, pp. 4485-4489. doi:10.1016/j.matdes.2010.04.045

[31] W. R. Osório, D. M. Rosa, L. C. Peixoto and A. Garcia, "Cell/Dendrite Transition and Electrochemical Corrosion of $\mathrm{Pb}-\mathrm{Sb}$ Alloys for Lead-Acid Battery Applications," Journal of Power Sources, Vol. 196, No. 15, 2011, pp. 6567-6572. doi:10.1016/j.jpowsour.2011.03.050 